\title{
Analisis Model Rasch Disposisi Matematis Mahasiswa pada Program Studi Pendidikan Matematika UMRAH
}

\author{
Nur Asma Riani Siregar ${ }^{1 *}$, Susanti $^{2}$, Mariyanti Elvi ${ }^{3}$ \\ 1,2,3 Universitas Maritim Raja Ali Haji, Tanjungpinang, Kepulauan Riau 29111, Indonesia \\ Pengiriman: 07/Maret/2021; Diterima: 25/Maret/2021; Publikasi: 31/Maret/2021 \\ DOI: https://doi.org/10.31629/jg.v6i1.3118
}

\begin{abstract}
Abstrak
Disposisi matematis merupakan objek kajian psikologi yang ditunjukkan dalam bentuk kecenderungn sikap, keyakinan, penilaian dan tindakan peserta didik terhadap matematika maupun hal yang berkaitan dengan matematika. Pengukuran disposisi matematis menggunakan instrumen angket skala likert dengan luaran berupa data ordinal. Data ordinal tidak memiliki linearitas pada skalanya sehingga jika digunakan dalam analisis statistik akan menghasilkan generalisasi yang tidak akurat. Salah satu model analisis data yang dapat menginterpretasikan data ordinal ke data interval dikenal dengan nama Model Rasch. Penelitian ini bertujuan untuk mendeskripsikan profil disposisi matematis yang dimiliki mahasiswa pada Program Studi Pendidikan Matematika UMRAH. Subjek yang diteliti adalah 65 orang mahasiswa Prodi Pendidikan Matematika UMRAH pada kelas Kalkulus Integral Tahun Ajaran 2019/2020. Instrumen penelitian menggunakan angket disposisi matematis MDFI yang berisi 60 butir pernyataan. Namun, data item yang dianalisis hanya berjumlah 58 item. Hal ini dikarenakan item i15 merupakan pernyataan negatif dari item i52 dan item i55 merupakan pernyataan ulang dari item i20. Analisis data menggunakan model analisis Rasch. Hasil penelitian menunjukkan 51,6\% responden memiliki disposisi matematis sedang, 40,3\% responden memiliki disposisi matematis tinggi dan $8,1 \%$ responden memiliki disposisi sangat tinggi. Nilai rata-rata disposisi matematis antara pria dan wanita tidak memiliki perbedaan yang signifikan.
\end{abstract}

Kata kunci: disposisi matematis; model Rasch

\begin{abstract}
Mathematical disposition is an object of psychological study which is shown in the form of tendencies of attitudes, beliefs, assessments and actions of students towards mathematics and matters related to mathematics. Measurement of mathematical disposition using a Likert scale questionnaire instrument with the output in the form of ordinal data. Ordinal data does not have linearity on its scale so that if it is used in statistical analysis resulting inaccurate generalizations. One of the data analysis models that can interpret ordinal data into interval data is known as the Rasch Model. This study aims to describe the mathematical disposition profiles of students in Program Studi Pendidikan Matematika UMRAH. The subjects studied were 65 students of Pendidikan Matematika UMRAH in the Integral Calculus class for the 2019/2020 academic year. The research instrument used the MDFI mathematical disposition questionnaire which contained 60 statement items. However, the data items analyzed were only 58 items. This is because item i15 is negatively worded repeat of item i52 and item i55 is repeat of item i20. Data analysis using the Rasch analysis model. The results showed $51.6 \%$ of respondents had moderate mathematical dispositions, $40.3 \%$ of respondents had high mathematical dispositions and $8.1 \%$ of respondents had very high mathematical dispositions. There is no significant difference in the mean between men and women.
\end{abstract}

Keywords: mathematical disposition; Rasch Model

*Penulis Korespondensi

Email Address: nur_asmariani@umrah.ac.id

Handphone : :6281387772793 


\section{JURNAL GANTANG. Maret 2021; VI(1): 1 - 10 \\ p-ISSN. 2503-0671 \\ e-ISSN. 2548-5547}

\section{Pendahuluan}

Salah satu tujuan dari pendidikan tinggi menurut Undang-undang Nomor 12 Tahun 2012 adalah mencetak lulusan yang memiliki penguasaan suatu cabang ilmu pengetahuan dan/atau teknologi demi kepentingan nasional dan meningkatkan daya saing bangsa di tingkat internasional. Setiap program studi yang terdapat di setiap pendidikan tinggi mencanangkan agar lulusan prodi nya memiliki penguasaan ilmu pengetahuan dan tekologi khususnya yang terkait dengan bidang ilmunya. Disamping itu, setiap pendidikan tinggi membekali dan memfasilitasi peserta didiknya untuk dapat mengembangkan dan mengasah keterampilan softskill yang dimilikinya sehingga lulusannya siap bergabung dan beradaptasi dengan dunia kerja.

Salah satu kompetensi lulusan pada program studi Pendidikan Matematika UMRAH yang tertuang dalam dokumen kurikulum K19 adalah menguasai objek matematika dalam setiap cabang Matematika baik level sekolah menengah maupun perguruan tinggi. Penguasaan objek matematika tersebut merupakan hasil belajar yang diperoleh peserta didik melalui kegiatan pembelajaran.

Banyak hal yang dapat mempengaruhi hasil belajar peserta didik. Salah satunya adalah disposisi matematis yang dimiliki peserta didik. Hal ini didasarkan pada hasil penelitian Saija (2012) yang menunjukkan adanya korelasi positif yang bernilai nyata antara disposisi matematis dengan hasil belajar matematika yang dicapai peserta didik. Hasil tersebut memberikan implikasi bahwa semakin tinggi disposisi matematis yang dimiliki peserta didik maka semakin tinggi pula hasil belajar matematika yang dicapai oleh peserta didik tersebut. Temuan ini didukung oleh hasil penelitian Mata et.al (2012) yang menyimpulkan bahwa peserta didik dengan prestasi matematika rendah memiliki sikap terhadap matematika lebih rendah dibandingkan dengan peserta didik yang memiliki prestasi matematika sedang atau tinggi. Hal senada ditemukan oleh Beyers (2012) melalui penelitiannya terhadap 107 orang mahasiswa calon guru di Atlantik Tengah. Hasil penelitian Beyers menemukan bahwa peserta didik dengan hasil belajar matematika rendah atau sedang cenderung memiliki disposisi matematis yang lebih rendah dibanding siswa dengan hasil belajar matematika tinggi.

Sejumlah hasil penelitian dari beberapa peneliti di atas menunjukkan bahwa disposisi matematis yang dimiliki peserta didik memiliki peranan penting terhadap pencapaian hasil belajar matematika yang diperolehnya. Feldhaus (2014) melalui penelitiannya menyimpulkan bahwa disposisi matematis sebagai salah satu kunci keberhasilan pembelajaran matematika. Oleh karena itu, selayaknyalah seorang pendidik menaruh perhatian besar terhadap disposisi matematis yang dimiliki peserta didiknya agar dapat menyajikan pembelajaran yang tepat guna untuk mendukung keberhasilan kegiatan pembelajaran dan peningkatan hasil belajar peserta didik.

Disposisi matematis dapat diartikan sebagai sikap, keyakinan, penilaian dan tindakan peserta didik terhadap matematika maupun hal terkait dengan matematika. Disposisi matematis siswa menurut Beyers (2011) muncul dalam bentuk kecenderungan-kecenderungan yang ada dalam diri peserta didik ketika dihadapkan pada hal-hal berkaitan dengan matematika maupun pada saat belajar matematika. Kecenderungan tersebut antara lain kecenderungan untuk melakukan koneksi dan argumentasi matematis, kecenderungan memiliki penilaian dan pandangan yang baik tentang matematika, kecenderungan untuk menghargai kegunaan matematika dan kecenderungan melakukan tindakan produktif dalam belajar matematika.

Disposisi matematis merupakan objek kajian psikologi yang dapat diukur dengan menggunakan instrumen jenis angket berisi pernyataan-pernyataan yang dapat mengungkap informasi disposisi yang dimiliki peserta didik. Instrumen angket tersebut disusun dengan menggunakan skala likert yang menghasilkan data ordinal. Pada data ordinal linearitas antar skala yang digunakan tidak sama, sehingga nilai 
skor total tidak dapat digunakan dalam perhitungan analisis statistik parametrik (Bond \& Fox, 2015; Boone et al., 2014; Engelhard, 2013). Oleh karena itu, data ordinal perlu diolah terlebih dahulu sehingga menghasilkan data yang linear antar setiap skalanya (Boone, 2016).

Rasch model merupakan salah satu model analisis data yang menggunakan pendekatan teori respon butir (IRT). Model Rasch melakukan interpretasi data ordinal menjadi data interval dalam skala logit (log of unit). Hasil interpretasi data dalam skala interval dapat digunakan dalam analisis statistik untuk mendapatkan kesimpulan yang lebih akurat (Febrian \& Fera, 2019; Salzberger \& Koller, 2013). Model Rasch juga mampu memberikan prediksi nilai item setiap responden sama dengan level ability nya. Responden dengan karakteristik lebih banyak condong terhadap variabel yang diamati akan memiliki skor yang lebih tinggi (Cavanagh \& Waugh, 2011).

Model Rasch memiliki keunggulan dibandingkan teori tes klasik yaitu kemampuan memprediksi data yang hilang berdasarkan pola respon individu (Sumintono \& Widhiarso, 2014). Sehingga, data respon individu yang memiliki missing data tetap dapat diperhitungkan dalam proses analisis. Nilai standar error pengukuran dari instrumen yang digunakan dapat diketahui secara cepat dengan model Racsh. Nilai standar error ini dapat digunakan untuk meningkatkan keakuratan pengukuran data.

Penelitian ini fokus pada variabel disposisi matematis peserta didik. Penelitian tentang variabel ini merupakan topik kajian yang cukup populer dikalangan peneliti di Indonesia (Mandur et al., 2013; Rahayu \& Kartono, 2014; Siregar et al., 2018; Sumirat, 2014; Syaban, 2009). Perbedaan utama dengan penelitian ini adalah metode analisis hasil angket yang digunakan sebagai instrumen penelitian. Jika pada penelitian yang dilakukan beberapa peneliti di atas menggunakan analisis metode klasik, maka pada penelitian ini metode analisis hasil angket yang digunakan adalah model Rasch. Perbedaan lain terletak pada tingkat pendidikan subjek yang diteliti.

Subjek penelitian adalah mahasiswa Program Studi Pendidikan Matematika UMRAH yang mengambil mata kuliah Kalkulus Integral pada Semester Genap Tahun Ajaran 2019/2020. Tujuan penelitian adalah untuk mendeskripsikan profil disposisi matematis mahasiswa Prodi Pendidikan Matematika UMRAH pada Mata Kuliah Kalkulus Integral. Data disposisi matematis dikumpulkan dengan menggunakan instrumen angket disposisi matematis MDFI yang dikembangkan oleh James Beyers dan akan dianalisis menggunakan pemodelan Rasch berbantu aplikasi Winstep 3.73.

Penelitian ini akan menghasilkan deskripsi data profil disposisi subjek yang diteliti, yaitu mahasiswa pada Program Studi Pendidikan Matematika UMRAH. Penelitian ini menjadi penting karena dengan tersedianya data profil disposisi matematis yang dimiliki mahasiswa sejak dini akan berdampak pada semakin cepat pula dosen dapat memanfaatkan informasi profil disposisi matematis tersebut dalam perencanaan pembelajara maupun dalam perancangan bahan ajar yang tepat bagi mahasiswanya.

\section{Metode Penelitian}

Penelitian ini bertujuan untuk mendeskripsikan profil disposisi matematis peserta didik dengan menggunakan analisis model Rasch. Penelitian ini merupakan penelitian deskriptif kuantitatif dengan subjek yang diteliti adalah 65 orang mahasiswa pada Program Studi Pendidikan Matematika UMRAH yang mengambil mata kuliah Kalkulus Integral pada semester genap Tahun Aajaran 2019/2020. Istrumen penelitian menggunakan angket disposisi matematis MDFI (Mathematics Dispositional Functions Inventory) yang dikembangkan oleh Beyers (2011). Instrumen MDFI mengukur disposisi matematis berdasarkan 3 (tiga) aspek yaitu kognitif, afektif dan konatif. Terdapat 10 (sepuluh) sub kategori disposisi matematis yang diukur seperti disajikan pada Tabel 1. 


\section{JURNAL GANTANG. Maret 2021; VI(1): 1 - 10 \\ p-ISSN. 2503-0671 \\ e-ISSN. 2548-5547}

Instrumen angket MDFI terdiri dari 60 butir pernyataan dengan menggunakan skala likert. Data item yang dianalisis hanya berjumlah 58 item. Hal ini dikarenakan item i15 merupakan pernyataan negatif dari item i52 dan item i55 merupakan pernyataan ulang dari item i20. Data kedua item ini dapat digunakan untuk melihat konsistensi pilihan responden (Beyers, 2012).

Terdapat 5 (lima) alternatif pilihan jawaban yang disediakan yaitu Sangat Setuju, Setuju, Netral, Tidak Setuju dan Sangat Tidak

Tabel 1.

Kategori disposisi matematis dan sebaran item angket
Setuju. Pernyataan positif diberi skor 5 untuk jawaban Sangat Setuju dan skor 1 untuk jawaban Sangat Tidak Setuju. Sebaliknya, pernyataan negatif diberi skor 1 untuk jawaban Sangat Setuju dan skor 5 untuk jawaban Sangat Tidak Setuju. Sebelum disebarkan kepada responden, instrumen angket terlebih dahulu diterjemahkan ke dalam Bahasa Indonesia dan divalidasi oleh 2 (dua) orang dosen ahli Bahasa, yaitu dosen Bahasa Inggris dan dosen Bahasa Indonesia.

\begin{tabular}{|c|c|c|c|c|}
\hline Kategori & Sub Kategori & Deskripsi & Kode Item & Jumlah \\
\hline \multirow[t]{2}{*}{ Kognitif } & Connection & $\begin{array}{l}\text { Kecenderungan untuk menghubungkan ide } \\
\text { dengan atau antar topik dalam matematika. }\end{array}$ & $\begin{array}{l}\text { i19, i27, i29, } \\
\text { i51, i53 }\end{array}$ & 5 \\
\hline & Argumentation & $\begin{array}{l}\text { Kecenderungan untuk mengevaluasi kebenaran } \\
\text { dari pernyataan, membuat argumentasi dan } \\
\text { menarik kesimpulan. }\end{array}$ & $\begin{array}{l}\text { i12, i14, i18, } \\
\text { i26, i48 }\end{array}$ & 5 \\
\hline \multirow[t]{7}{*}{ Afektif } & $\begin{array}{l}\text { nature of } \\
\text { mathematics }\end{array}$ & $\begin{array}{l}\text { Kecenderungan memiliki penilaian bahwa } \\
\text { matematika bersifat prosedural atau } \\
\text { konseptual. }\end{array}$ & $\begin{array}{l}\mathrm{i} 6, \mathrm{i} 13, \mathrm{i} 21, \mathrm{i} 31 \\
\mathrm{i} 33, \mathrm{i} 35, \mathrm{i} 38, \\
\mathrm{i} 41, \mathrm{i} 45, \mathrm{i} 58\end{array}$ & 10 \\
\hline & usefulness & $\begin{array}{l}\text { Kecenderungan memiliki keyakinan bahwa } \\
\text { matematika berguna dalam kehidupan sehari- } \\
\text { hari atau dimasa yang akan datang. }\end{array}$ & $\begin{array}{l}\mathrm{i} 2, \mathrm{i} 3, \mathrm{i} 5, \mathrm{i} 10, \\
\mathrm{i} 17, \mathrm{i} 20, \mathrm{i} 24, \\
\mathrm{i} 32, \mathrm{i} 34, \mathrm{i} 39 \\
\mathrm{i} 54, \mathrm{i} 55\end{array}$ & 12 \\
\hline & worthwhileness & $\begin{array}{l}\text { Kecenderungan untuk meyakini bahwa usaha } \\
\text { yang diberikan dalam belajar matematika akan } \\
\text { membuahkan hasil. }\end{array}$ & $\mathrm{i} 4, \mathrm{i} 16, \mathrm{i} 50$ & 3 \\
\hline & sensibleness & $\begin{array}{l}\text { Kecenderungan memiliki keyakinan bahwa } \\
\text { matematika terdiri dari sejumlah ide yang } \\
\text { dapat dipahami. }\end{array}$ & $\mathrm{i} 25, \mathrm{i} 44, \mathrm{i} 47, \mathrm{i} 60$ & 4 \\
\hline & $\begin{array}{l}\text { mathematics } \\
\text { self-concept }\end{array}$ & $\begin{array}{l}\text { Kecenderungan untuk meyakini kemampuan } \\
\text { diri dalam melakukan tugas-tugas matematika. }\end{array}$ & $\begin{array}{l}\text { i7, i28, i30, i40, } \\
\mathrm{i} 46, \mathrm{i} 59\end{array}$ & 6 \\
\hline & attitude & $\begin{array}{l}\text { Kecenderungan suka/tidak suka dengan hal } \\
\text { yang berkaitan dengan matematika. }\end{array}$ & $\begin{array}{l}\text { i11, i15, i49, } \\
\text { i52, i56 }\end{array}$ & 5 \\
\hline & math anxiety & $\begin{array}{l}\text { Kecenderungan munculnya rasa gelisah yang } \\
\text { berhubungan dengan matematika. }\end{array}$ & $\begin{array}{l}\text { i1, i9, i37, i42, } \\
\text { i57 }\end{array}$ & 5 \\
\hline Konatif & effort/persistence & $\begin{array}{l}\text { Kecenderungan untuk gigih dan tekun dalam } \\
\text { melakukan tugas matematika. }\end{array}$ & $\begin{array}{l}\text { i8, i22, i23, i36, } \\
\text { i43 }\end{array}$ & 5 \\
\hline
\end{tabular}

Terdapat 4 (empat) tahap analisis yang dilakukan yaitu analisis misfit order item, analisis misfit person, analisis peta person dan item, serta kategorisasi nilai disposisi matematis. Tujuan dari masing-masing tahapan analisis disajikan pada Tabel 2.

Analisis misfit order item dan misfit person akan menghasilkan data item dan person yang fit dengan model Rasch untuk dianalisis pada tahap selanjutnya. Parameter yang dapat digunakan untuk mengetahui kesesuaian item maupun respon person dengan model Rasch adalah nilai outfit mean square (MNSQ) dan outfit Z-Standard (ZSTD).

Nilai parameter MNSQ untuk outfit item maupun person yang sesuai dengan model adalah $0,5<$ outfit $\mathrm{MNSQ}<1,5$. Sedangkan nilai ZSTD yang layak digunakan untuk perhitungan statistik adalah $-2<$ ZSTD $<2$ (Boone et al., 2014). Perhitungan statistik nilai ZTSD didasarkan pada 
nilai MNSQ, sehingga pada analisa nilai outfit disarankan agar dimulai dengan menganalisis nilai outfit MNSQ. Jika nilai outfit MNSQ sudah memenuhi kriteria kesesuaian model, maka nilai outfit ZSTD dapat diabaikan.

Tabel 2.

Tahap analisis data

\begin{tabular}{ll}
\hline \multicolumn{1}{c}{ Tahap analisis } & \multicolumn{1}{c}{ Tujuan } \\
\hline Misfit order item & $\begin{array}{l}\text { Mendapatkan data item } \\
\text { yang fit dengan model } \\
\text { Rasch }\end{array}$ \\
\hline Misfit person & $\begin{array}{l}\text { Mendapatkan data person } \\
\text { yang fit dengan model }\end{array}$ \\
& Rasch \\
\hline Map person-item & $\begin{array}{l}\text { Deskripsi disposisi } \\
\text { matematis dan tingkat }\end{array}$ \\
& $\begin{array}{l}\text { kesukaran item untuk } \\
\text { disetujui }\end{array}$ \\
\hline Kategorisasi nilai & $\begin{array}{l}\text { Pengelompokan responden } \\
\text { berdasarkan level diposisi }\end{array}$ \\
disposisi & matematisnya \\
\hline
\end{tabular}

Data data item dan person yang fit dengan model Rasch selanjutnya dianalisis secara bersmaan berdasarkan peta person dan item menggunakan data hasil Variable (Wright) Map. Analisis tahap akhir dengan menggunakan nilai person measure akan menghasilkan kategorisasi disposisi matematis mahasiswa. Pengelompokan level ability/agreement responden pada analisis Rasch dilakukan dengan memperhatikan level kesulitan item (Boone et al., 2014).

\section{Hasil dan Pembahasan \\ a. Analisis Misfit Order Item}

Analisis model Rasch mensyaratkan setiap item angket harus memenuhi kriteria kesesuaian model. Hasil diagnosis misfit item menunjukkan terdapat 13 item yang tidak sesuai dengan model, 12 item underfit dengan nilai parameter outfit MNSQ $>1,5$ dan 1 item overfit dengan nilai oufit MNSQ $<0,5$. Terhadap 13 item tersebut dilakukan pemeriksaan respon item untuk mencari respon yang diduga menjadi pemyebab misfit yaitu tipe respon yang di luar kebiasaan (odd respon). Suatu respon dikatakan odd respon jika memiliki nilai z-residual $\geq 2$ atau nilai zresidual $\leq-3$ (Boone et al., 2014).
Salah satu solusi mengatasi respon tidak terduga (odd respon) adalah dengan menghapus odd respon atau memberikan kode ' $\mathrm{x}$ ' pada respon item yang misfit. Setelah itu, dilakukan analisis ulang untuk melihat pengaruh perubahan data terhadap nilai outfit MNSQ (Boone et al., 2014). Metode ini menurut Boone et. al tidak hanya dapat meningkatkan keakuratan instrumen dalam melakukan pengukuran, namun juga dapat meningkatkan reliabilitas respon dari responden.

Analisis misfit item setelah melalui tahap eliminasi odd respon menunjukkan keseluruhan item (58 item) telah memenuhi parameter nilai outfit MNSQ dengan nilai outfit MNSQ berada pada selang $0,52 \leq \mathrm{MNSQ} \leq 1,48$. Oleh karena nilai outfit MNSQ sudah terpenuhi maka nilai outfit ZSTD tidak perlu dianalisis lagi. Hal ini didasarkan pendapat Boone et. al (2014) yang mengemukakan jika nilai outfit MNSQ sudah memenuhi kriteria kesesuaian model, maka nilai outfit ZSTD dapat diabaikan. Statistik deskriptif data item angket disajikan pada Gamar 1.

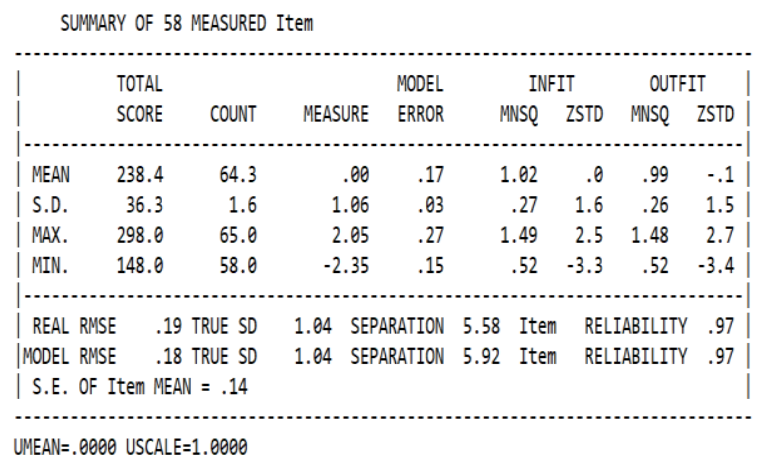

Gambar 1. Deskriptif data item

Nilai item realibility sebesar 0,97 menunjukkan kualitas butir-butir pernyataan dalam angket sudah dibuat dengan baik sekali dan reliabel digunakan untuk mengumpulkan data disposisi matematis. Reliabilitas instrumen lebih lanjut dapat dilihat berdasarkan nilai indeks separation (Mahmud \& Porter, 2015). Indeks separation sebesar 5,58 (dibulatkan menjadi 6) menunjukkan bahwa terdapat 6 (enam) kelompok item berdasarkan tingkat kesulitan responden untuk menyetujui butir-butir pernyataan angket, dari yang paling mudah disetujui ke yang paling 


\section{JURNAL GANTANG. Maret 2021; VI(1): 1 - 10 \\ p-ISSN. 2503-0671 \\ e-ISSN. 2548-5547}

sulit disetujui oleh responden. Berdasarkan penjelasan di atas, dapat disimpulkan bahwa keseluruhan data item sudah memenuhi syarat kesesuaian model.

\section{b. Analisis Misfit Person}

Analisis misfit person merupakan analisis untuk mengkaji apakah respon person memenuhi kriteria kesesuaian model Rasch. Analisis ini didasarkan pada nilai MNSQ dan ZSTD person. Hasil analisis menunjukkan terdapat 9 (sembilan) responden yang tidak sesuai dengan model Rasch. Enam respoden yaitu R02, R18, R34, R60, R61 dan R63 memiliki pola respon diluar kebiasaan tipe underfit dengan nilai MNSQ>1,5 dan ZSTD $>2$. Sedangkan 3 (tiga) responden lainnya yaitu R30, R40 dan R52 memiliki pola respon overfit dengan nilai outfit $\mathrm{MNSQ}<0,5$ dan outfit ZSTD<-2. Batas misfit normal menurut Boone et.al ( 2014) adalah 5\% dari jumlah data. Artinya, batas data responden yang tidak sesuai model pada penelitian ini maksimal 3 responden. Oleh sebab itu, misfit person sebanyak 9 responden sudah diluar batas normal.

Respon tidak fit menunjukkan model Rasch tidak mampu memprediksi data responden dengan baik. Solusi umum yang dapat dilakukan untuk mengatasi masalah misfit adalah dengan mengeluarkan data misfit dari proses analisis (Boone \& Noltemeyer, 2017). Pada penelitian ini, peneliti melakukan proses eliminasi data responden misfit dengan satu persatu, kemudian melihat pengaruhnya terhadap nilai parameter fit model Rasch.

Eliminasi data reponden dimulai dari data dengan nilai outfit tertinggi yaitu responden R34. Hasil analisis misfit data menunjukkan 5 responden masih dalam kategori misfit. Eliminasi data responden kedua yaitu R63 juga masih menyisakan misfit data dari 5 responden. Pada eliminasi ketiga yaitu data R60 diperoleh hasil responden dengan misfit data tersisa 3 orang. Karena jumlah ini merupakan batas misfit 5\% dari 62 person yang tersisa, maka proses eliminasi dihentikan. Dengan demikian, analisis misfit person menghasilkan data 62 responden yang memenuhi kriteria kesesuain model. Statistik deskriptif data person dari 62 responden disajikan pada Gambar 2.

Nilai rata-rata responden sebesar 1,30 logit dengan standar deviasi sebesar 0,89. Indeks reliabilitas sebesar 0,95 menunjukkan konsistensi jawaban responden terhadap butir-butir pernyataan angket sangat kuat. Nilai indeks separation sebesar 4,35 (dibulatkan menjadi 4) menunjukkan bahwa terdapat empat kelompok responden berdasarkan level disposisi matematis yang dimilikinya

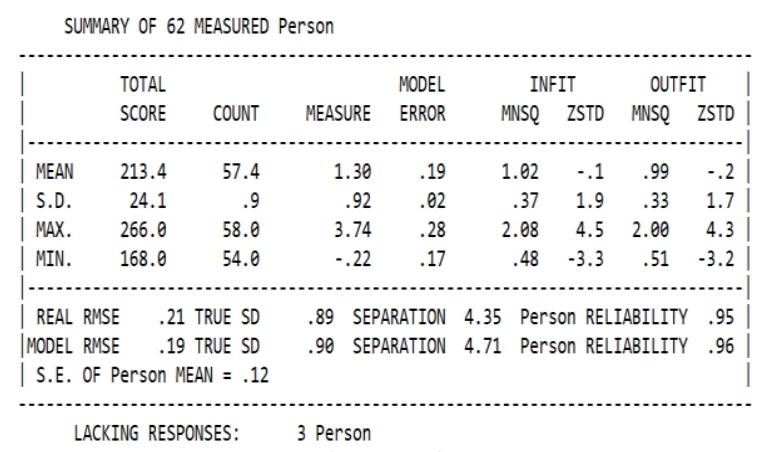

Gambar 2. Statistik deskriptif Person

\section{c. Analisis Peta Person dan Item}

Analisis peta person dan item pada model Rasch didasarkan pada hasil Variable (Wright) Map yang disajikan pada Gambar 3. Nilai logit person dan item berada pada skala logit yang sama. Nilai logit person diurutkan dari terkecil hingga terbesar menunjukkan nilai disposisi matematis dari terendah hingga tertinggi. Sedangkan nilai logit item dari terkecil hingga terbesar menunjukkan item yang paling mudah disetujui hingga item dengan urutan paling sukar untuk disetujui oleh responden.

Pada Gambar 3 dapat dilihat nilai ratarata responden sebesar 1,30 logit, sedangkan nilai rata-rata item 0,0 logit (nilai rata-rata item model Rasch). Nilai rata-rata person lebih tinggi dibanding nilai rata-rata item menunjukkan bahwa pada umumnya responden cenderung menyetujui isi butir-butir pernyataan angket. Item i20 merupakan pernyataan termudah untuk disetujui oleh responden. Hal ini berarti bahwa pada umumnya responden menyetujui bahwa sebagai seorang calon guru matematika mereka harus menguasai matematika. Sebaliknya, item 
i24 merupakan pernyataan yang kurang diminati oleh responden. Hal ini mengindikasikan bahwa menurut responden kegunaan matematika dalam kehidupan sehari-hari tidak hanya sebatas menyelesikan permasalahan yang berkaitan dengan uang.

Seseorang yang memiliki keyakinan bahwa matematika berguna dan manfaat bagi dirinya akan memiliki penilaian yang baik terhadap matematika. Penelitian Beyers (2005) menemukan bahwa calon guru yang ia teliti memiliki keyakinan bahwa matematika yang mereka pelajari di pendidikan keguruan akan sangat berguna bagi karir profesionalnya. Pada umumnya, mahasiswa yang memilih jurusan pendidikan matematika memiliki rencana akan meniti karir di bidang matematika setelah lulus kuliah, khususnya sebagai guru matematika. Artinya, sejak awal mereka sudah sadar akan kegunaan matematika bagi masa depannya. Sebagai calon guru matematika tentu harus memiliki penguasaaan ilmu matematika yang baik. Oleh karena itu, sangatlah wajar jika responden yang merupakan mahasiswa prodi pendidikan matematika secara keseluruhan cenderung menyetujui item i20 dan kurang setuju dengan item i24.

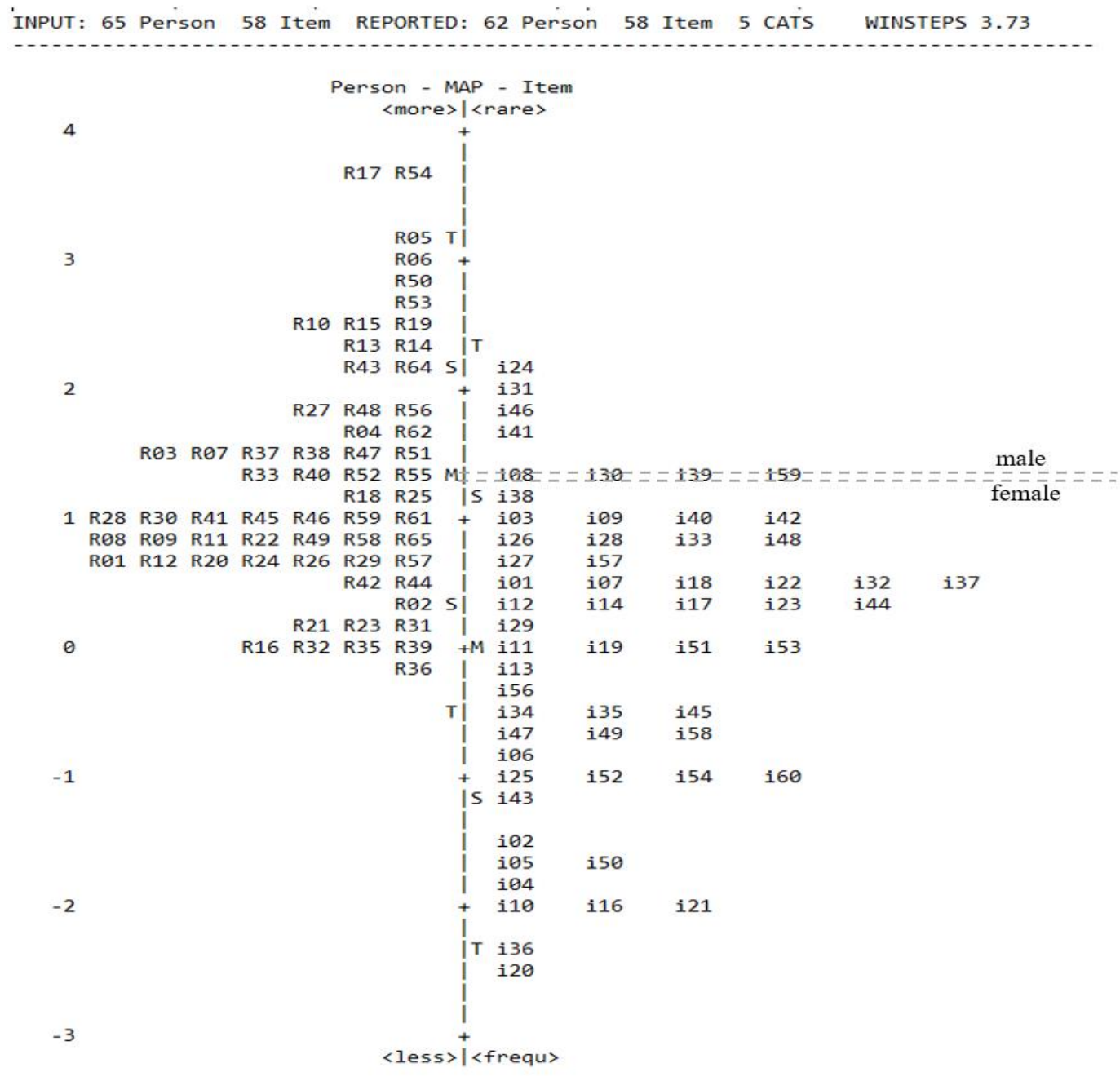

Gambar 3. Peta Person dan Item

Responden R17 dan R54 merupakan dua responden dengan nilai tertinggi yaitu secara berurutan 3,74 logit dan 3,68 logit. Hal ini berarti kedua responden tersebut merupakan responden dengan nilai disposisi matematis tertinggi peringkat satu dan dua. Sedangkan responden 
JURNAL GANTANG. Maret 2021; VI(1): 1 - 10

p-ISSN. 2503-0671

e-ISSN. 2548-5547

dengan disposisi matematis paling rendah diantara keseluruhan responden adalah R34 dengan nilai $-0,22$ logit.

Seorang yang memiliki disposisi matematis tinggi memiliki sikap dan keyakinan yang baik terhadap matematika. Peserta didik dengan disposisi matematis tinggi cenderung memandang matematika sebagai suatu yang logis, berguna dan bermanfaat (Beyers, 2011; Feldhaus, 2014; Rahayu \& Kartono, 2014), memiliki kebiasaan untuk menggunakan penalaran pada saat belajar, serta menghargai dan bersedia memberikan usaha yang lebih dalam belajar matematika (Beyers, 2011; Beyers, 2012). Kebiasaan bernalar dapat melatih keterampilan berpikir. Kebiasaan meluangkan waktu dan memberikan usaha yang lebih saat belajar akan memberikan kesempatan yang besar untuk mengenal dan menguasai matematika secara mendalam. Peserta didik yang dengan disposisi matematis tinggi juga menyenangi kegiatan belajar matematika (Graven, 2015).

Nilai rata-rata disposisi matematis responden pria berdasarkan Gambar 3 sebesar 1,31 logit. Sedangkan nilai rata-rata responden wanita sedikit lebih rendah disbanding pria yaitu sebesar 1,29 logit. Namun, hasil uji Kruskall Wallis menunjukkan perbedaan nilai rata-rata pria dengan wanita tersebut tidak memiliki arti yang signifikan ( $p$.value $=0,7<0,05$ ).

\section{d. Kategorisasi Disposisi Matematis}

Pengelompokan level ability/agreement responden pada analisis Rasch dilakukan dengan memperhatikan level kesulitan item (Boone et al., 2014). Pedoman kategori disposisi matematis disajikan pada Tabel 3.

Tabel 3.

Pedoman kategorisasi disposisi matematis

\begin{tabular}{cc}
\hline Measure $(m)$ & Kategori \\
\hline$m>2,87$ & Sangat Tinggi \\
\hline $1,02<m \leq 2,87$ & Tinggi \\
\hline$-0,63<m \leq 1,02$ & Sedang \\
\hline$-2,12<m \leq-0,63$ & Rendah \\
\hline$-2,12 \leq m$ & Sangat Rendah \\
\hline
\end{tabular}

Dengan mengikuti pedoman kategorisasi pada Tabel 3 maka 62 responden yang fit dengan model Rasch terbagi atas tiga kategori disposisi matematis yaitu sangat tinggi, tinggi dan sedang. Banyak responden pada masing-masing kategori disajikan pada Tabel 4.

Tabel 4.

Kategori disposisi matematis responden

\begin{tabular}{ccc}
\hline Kategori & Banyak & Persentase \\
\hline Sangat Tinggi & 5 & $8,1 \%$ \\
\hline Tinggi & 25 & $40,3 \%$ \\
\hline Sedang & 32 & $51,6 \%$ \\
\hline
\end{tabular}

Berdasarkan Tabel 4 dapat disimpulkan bahwa secara keseluruhan mahasiswa pada Program Studi Pendidikan Matematika UMRAH pada mata kuliah Kalkulus Integral Tahun Ajaran 2019/2020 memiliki disposisi matematis cukup baik yaitu berada pada level sedang ke tinggi. Hal yang harus menjadi bahan perhatian bagi dosen di prodi terkait adalah lebih dari 50\% mahasiswa yang diteliti memiliki disposisi matematis pada level sedang. Hal ini berimplikasi bahwa lebih dari setengah mahasiswa belum memiliki penilaian dan pandangan yang baik terhadap matematika, serta belum memberikan usaha yang terbaik dalam belajar matematika.

Feldhaus (2014) mengungkapkan bahwa disposisi matematis yang dimiliki seorang guru akan berdampak pada bagaimana guru tersebut merencanakan dan melaksanakan pembelajaran. Lebih lanjut, ia mengungkapkan seorang guru yang memiliki disposisi matematika yang rendah dikhawatirkan akan mentransfer kecemasan matematika yang dialaminya kepada siswa yang diajarnya. Hal ini berarti bahwa, disposisi matematis yang dimiliki mahasiswa calon guru kelak dapat berdampak pada disposisi matematis peserta didik yang diajarnya. Oleh karena itu, dosen di Prodi Pendidikan Matematika UMRAH khususnya yang mengajar kelompok mahasiswa yang diteliti, perlu memikirkan suatu cara efektif atau merencanakan suatu pembelajaran yang dapat mengembangkan disposisi matematis kelompok mahasiswa tersebut. 
Hasil penelitian ini dapat menjadi referensi bagi dosen Prodi Pendidikan Matematika UMRAH terkait data profil disposisi matematis mahasiswa. Data tersebut dapat menjadi bahan pertimbangan bagi dosen pada saat perencanaan pembelajaran maupun dalam hal perancangan bahan ajar yang produktif bagi mahasiswanya. Dosen pengajar mahasiswa di pendidikan keguruan disarankan agar senantiasa mempromosikan pentingnya seorang mahasiswa calon guru khususnya calon guru matematika memiliki disposisi matematis yang tinggi. Dosen juga disarankan agar menyajikan pembelajaran yang berpotensi pada pengembangan disposisi matematis mahasiswa yang diajarnya.

\section{Kesimpulan}

Analisis model Rasch mensyaratkan item angket harus memenuhi kriteria kesesuaian model. Hasil analisis misfit item menunjukkan keseluruhan item (58 item) memenuhi kriteria kesesuaian model. Hasil tersebut didapatkan setelah mengeliminasi data respon item yang memiliki nilai $z-$ residual $\geq 2$ atau $z-$ residual $\leq-3$.

Analisis misfit person tahap awal menghasilkan 9 data responden tidak sesuai model. Tindakan eliminasi secara berurutan data responden R34, R63 dan R60 menghasilkan 62 data responden yang layak diproses pada tahap analisis selanjutnya.

Rata-rata nilai responden sebesar 1,30 logit, lebih tinggi dibanding nilai rata-rata item 0,0 logit. Hal ini menunjukkan bahwa secara keseluruhan responden cenderung menjawab setuju terhadap butir-butir pernyataan angket. Rata-rata nilai responden pria sebesar 1,31 logit dan rata-rata responden wanita 1,28 logit. Namun, uji Kruskall Wallis dengan SPSS menunjukkan tidak terdapat perbedaan nilai rata-rata yang signifikan antara pria dengan wanita $(p$.value $=$ $0,7<0,05)$.

Disposisi matematis dari 62 responden yang fit dengan model Rasch dikelompokkan ke dalam 3 (tiga) kategori yaitu sedang, tinggi dan sangat tinggi. Dengan rincian, 51,6\% responden memiliki disposisi matematis sedang, 40,3\% responden memiliki disposisi matematis tinggi dan $8,1 \%$ responden memiliki disposisi sangat tinggi. Hasil penelitian ini dapat dimanfaatkan sebagai sumber referensi bagi dosen pada saat akan merancang pembelajaran maupun bahan ajar yang efektif dan efisien di Prodi Pendidikan Matematika UMRAH.

\section{Ucapan Terimakasih}

Ucapan terima kasih penulis sampaikan kepada tim dosen pengampu mata kuliah Kalkulus integral di Prodi Pendidikan Matematika UMRAH yang telah memberi dukungan dan bantuan pada penelitian ini. Penulis juga mengucapkan terimakasih kepada mahasiswa Prodi Pendidikan Matematika UMRAH khususnya mahasiswa pada kelas Kalkulus Integral T.A. 2019/2020 yang telah bersedia menjadi responden pada penelitian ini.

\section{Referensi}

Beyers, J. (2011). Development and evaluation of an instrument to asses prospective teachers' disposition with respect of mathematics. International Journal of Business and Science, 2(16), 20-32.

Beyers, J. E. R. (2012). An examination of the relationship between prospective teachers' dispositions and achievement in a mathematics content course for elementary education majors. SAGE Open. https://doi.org/10.1177/2158244012462589

Beyers, J. E. R. (2005). What counts as "productive" dispositions among preservice teachers? Proceedings of the 27th Annual Meeting of the North American Chapter of the International Group for the Psychology of Mathematics Education, 130-131.

Bond, T. G., \& Fox, C. M. (2015). Applying the Rash Model: Fundamental in the Human Sciences. (Third Edit). Routledge.

Boone, W. J. (2016). Rasch analysis for instrument development: why, when, and how? CBCE Life Sciences Education, 15(4). https://doi.org/10.1187/cbe.16-04-0148

Boone, W. J., \& Noltemeyer, A. (2017). Rasch analysis: A primer for school psychology 
JURNAL GANTANG. Maret 2021; VI(1): 1 - 10

p-ISSN. 2503-0671

e-ISSN. 2548-5547

researchers and practitioners. In Cogent Education.

https://doi.org/10.1080/2331186X.2017.14 16898

Boone, W. J., Staver, J. R., \& Yale, M. S. (2014). Rasch Analysis in the Human Sciences. Springer.

Cavanagh, R. F., \& Waugh, R. F. (2011). The utility of rasch measurement for learning environments research. In Applications of Rasch Measurement in Learning Environments Research. https://doi.org/10.1007/978-94-6091-4935_1

Engelhard, G. (2013). Invariant measurement: Using Rasch models in the social, behavioral, and health sciences. In Invariant Measurement: Using Rasch Models in the Social, Behavioral, and Health Sciences. https://doi.org/10.4324/9780203073636

Febrian, \& Fera, M. (2019). Kualitas perangkat dan keterampilan mengajar mahasiswa pendidikan matematika pada mata kuliah micro teaching menggunakan analisis model rasch. Jurnal Gantang, 4(1), 87-95. https://doi.org/10.31629/jg.v4i1.1065

Feldhaus, C. A. (2014). How pre service elementary school teachers' mathematical dispositions are influenced by school mathematics. American International Journal of Contemporary Research, 4(6), 91-97.

Graven, M. (2015). Strengthening maths learning disposition through "math club." South African Journal of Childhood Education, 5(3). https://doi.org/10.4102/sajce.v5i3.342

Mahmud, Z., \& Porter, A. (2015). Using rasch analysis to explore what students learn about probability concepts. Journal on Mathematics Education. https://doi.org/10.22342/jme.6.1.1937.1-10

Mandur, K., Sadra, I. W., \& I Nengah Suparta. (2013). representasi , dan disposisi matematis terhadap prestasi belajar matematika. E-Journal.

Mata, M. de L., Monteiro, V., \& Peixoto, F. (2012). Attitude toward Mathematics: Effect of Individual, Motivational, and Social Support Factors. Child Development Research,2012.

https://doi.org/10.1155/2012/876028
Rahayu, R., \& Kartono. (2014). The effect of mathematical disposition toward problem solving ability based on IDEAL problem solver. International Journal of Science and Research.

Saija, L. M. (2012). Analyzing the mathematical disposition and its correlation with mathematics achievement of senior high school students. Infinity Jurnal Ilmiah Program Studi Matematika STKIP Siliwangi Bandung, 1(2), 148-152.

Salzberger, T., \& Koller, M. (2013). Towards a new paradigm of measurement in marketing. Journal of Business Research, 66(9),1307-1317.

https://doi.org/10.1016/j.jbusres.2012.02.03 0

Siregar, N. A. R., Deniyanti, P., \& Hakim, L. El. (2018). Pengaruh model pembelajaran CORE terhadap kemampuan berpikir kritis dan disposisi matematis ditinjau dari kemampuan awal matematika siswa SMA Negeri di Jakarta Timur. Jurnal Penelitian Dan Pembelajaran Matematika (JPPM), 11(1),187-196. https://doi.org/10.30870/jppm.v11i1.2997

Sumintono, B., \& Widhiarso, W. (2014). Aplikasi Model Rash untuk Penelitian Ilmu-ilmu Sosial. Tim Komunikata Publishing House.

Sumirat, L. A. (2014). Efektifitas strategi pembelajaran kooperatif tipe Think-TalkWrite (TTW) Terhadap Kemampuan Komunikasi dan Disposisi Matematis Siswa. Jurnal Pendidikan Dan Keguruan, 1(2), 21-29.

Syaban, M. (2009). Menumbuhkembangkan daya dan disposisi matematis siswa sekolah menengah atas melalui pembelajaran investigasi. EDUCATIONIST, 3(2), 129136. 